\title{
Trunk Posture Adaptations during Sitting on Dynamic Stool: A Validation Study
}

\author{
Alessandro Picelli ${ }^{1, *\left(\mathbb{D}, \text { Giuliano } \text { Mazzocco }^{2} \text { and Nicola Smania }\right.}{ }^{1}(\mathbb{D})$ \\ 1 Department of Neurosciences, Biomedicine and Movement Sciences, University of Verona, \\ 37100 Verona, Italy; nicola.smania@univr.it \\ 2 Polo Tecnico di Adria, 45011 Adria, Italy; giuliano2408@gmail.com \\ * Correspondence: alessandro.picelli@univr.it; Tel.: +39-045-812-4573
}

Received: 1 October 2020; Accepted: 24 October 2020; Published: 27 October 2020 updates

\begin{abstract}
Back pain is a complex condition that results from multiple factors including sitting issues such as the chair type and spinal sitting posture. The physiological spinal curvature on the sagittal plane represents a typical feature of good body posture. Sitting postures matching the physiological shape of the spine on the sagittal plane during standing are deemed advantageous from a postural point of view. The aim of this study was to validate a novel dynamic stool by comparing trunk posture adaptations on the sagittal plane during dynamic sitting vs. conventional sitting (standard stool) in healthy people. In total, 100 healthy adults were included. Age, sex and body mass index were recorded. Thoracic kyphosis and lumbar lordosis were measured with the IncliMed ${ }^{\circledR}$ goniometer during standing posture, conventional sitting posture (standard stool) and dynamic sitting posture (novel dynamic stool). Sitting posture was maintained for $2 \mathrm{~min}$ before evaluation. Thoracic kyphosis and lumbar lordosis were significantly different between standing vs. sitting (dynamic and conventional) posture $(p<0.001)$ and between dynamic vs. conventional sitting posture $(p<0.001)$. Sitting on the novel dynamic stool tested in this study was shown to provide a greater match of thoracic kyphosis and lumbar lordosis with the physiological spinal curvature on the sagittal plane during standing than conventional sitting.
\end{abstract}

Keywords: back; ergonomics; posture; sitting; spine

\section{Introduction}

Back pain is a leading cause of disability and a main contributor of disease burden worldwide [1,2]. Non-specific back pain (also called mechanical back pain) is the most common clinical presentation of back pain and refers to conditions without a known etiology [1,3]. Back pain is a complex condition that results from the interaction of multiple factors including physical issues (e.g., prolonged standing), unhealthy lifestyle (e.g., smoking and obesity), psychological factors (e.g., distress), manual tasks (e.g., heavy loads or lifting objects far from the body), awkward postures and genetic factors [4]. In addition, sitting issues (i.e., sitting duration, chair type, amount of spinal motion and spinal curvature during sitting) have been proposed as risk factors for the development of back pain [5]. The physiological sagittal spinal curvature represents a typical feature of good body posture [6]. As to standing, the presence of slight curves (thoracic kyphosis and lumbar lordosis) has been described as the "ideal" spinal posture on the sagittal plane [5-9]. On the other hand, despite the definition of the best sitting posture still being the object of debate, physiotherapists deem advantageous those sitting postures that match the natural shape of the spine [7-9]. One of the most common strategies used by physiotherapists for managing back pain is to provide some advice on spinal postures. In particular, addressing sitting spinal posture may help reduce symptoms of patients with back pain $[8,9]$. Dynamic chairs have been proposed to address the negative effects of prolonged sitting by 
increasing the effort required to maintain sitting balance, stimulating posture variation, promoting lordotic lumbar postures and decreasing lumbar muscle tension [10].

The "EnergyBack" device is a newly patented dynamic stool (Italian Registry no. 102016000118233) that aims to improve sitting posture (see Figure 1). To date, this novel device has not yet been validated.

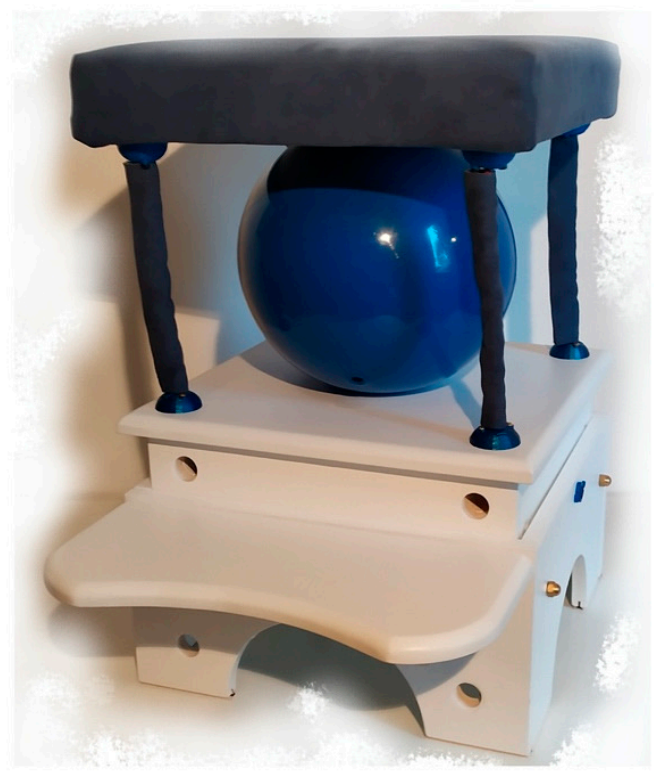

Figure 1. The "EnergyBack" dynamic stool.

The main aim of this study was to compare dynamic sitting vs. conventional sitting as to trunk posture adaptations on the sagittal plane (thoracic kyphosis and lumbar lordosis) in healthy people. Our study hypothesis was that thoracic kyphosis and lumbar lordosis during dynamic sitting would greater match the natural shape of the spine (i.e., spinal curves on the sagittal plane evaluated during standing) than conventional sitting on a standard stool.

\section{Materials and Methods}

This validation study included healthy adult (age greater than 18 years) volunteers. Exclusion criteria were: inclusion in other trials, pain involving any district (cervical, dorsal, lumbar or sacral) of the spine, congenital or acquired spine diseases (scoliosis, Scheuermann juvenile kyphosis, spinal muscular atrophy, arthritis, degenerative disc disease, ankylosing spondylitis, lumbar spinal stenosis, spina bifida, spinal tumors, osteoporosis and cauda equina syndrome), previous spine trauma (spinal fractures, sprains or muscle-ligament injuries), previous spine surgery, other spine conditions altering trunk posture. All volunteers gave their informed, written consent to participate in the study, which was carried out according to the Declaration of Helsinki and approved (approval number 08/2018) by the local ethics committee (CARU—Comitato di Approvazione per la Ricerca sull'Uomo-University of Verona).

\subsection{Evaluation Procedures}

The same physician evaluated all subjects and collected data about their age, sex and body mass index (BMI). The degrees of thoracic kyphosis and lumbar lordosis were measured on the sagittal plane by means of the IncliMed ${ }^{\circledR}$ goniometer [11]. Following the validated procedure for this tool, we placed it on three palpatory back landmarks corresponding to the first thoracic vertebra (T1), the twelfth thoracic vertebra (T12) and the second sacral vertebra (S2) [11,12]. Thoracic kyphosis was calculated by adding the T1 and T12 measures (degrees), while lumbar lordosis resulted from the addition of T12 and S2 measures (degrees) [11-13]. Thoracic kyphosis and lumbar lordosis were evaluated in three different 
conditions: standing posture (participants were instructed to stand relaxed "as you normally would"), conventional sitting posture (standard stool) and dynamic sitting posture ("EnergyBack" dynamic stool). In the sitting posture, participants were instructed to sit relaxed "as you normally would". The (standard and dynamic) stool height was adjusted according to the height of each patient in order to maintain feet flat on the floor and knees flexed to approximately 90 degrees during evaluation (see Figure 2). Sitting on the (standard and dynamic) stool was maintained for $2 \mathrm{~min}$ before evaluation in order to increase compliance.

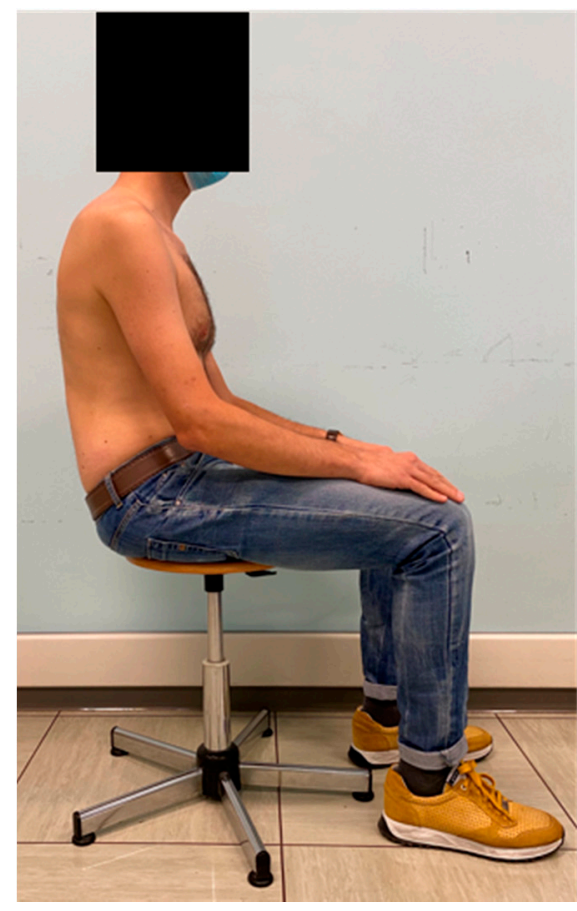

(a)

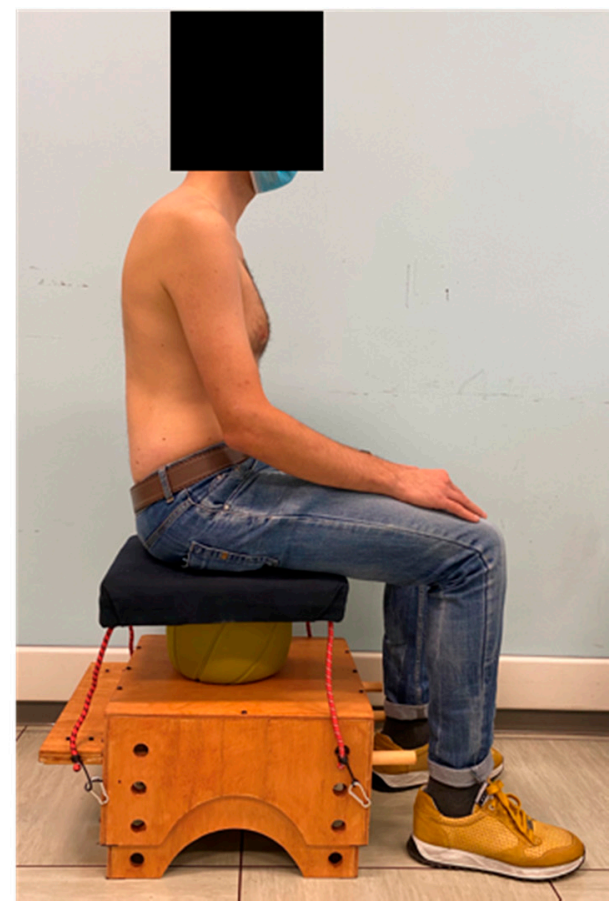

(b)

Figure 2. Sitting conditions for evaluation: (a) conventional sitting posture on a standard stool; (b) dynamic sitting posture on the "EnergyBack" dynamic stool (prototype).

\subsection{Statistical Analysis}

Statistical analysis was carried out using the Statistical Package for Social Science for Macintosh, version 26.0 (IBM SPSS Inc, Armonk, NY, USA).

We performed a univariate analysis of variance (ANOVA) to analyze the main effect of (standing and sitting) posture on thoracic kyphosis and lumbar lordosis. In the presence of significant main effects, post-hoc comparisons between different conditions (standing posture vs. conventional sitting posture; standing posture vs. dynamic sitting posture; conventional sitting posture vs. dynamic sitting posture) were analyzed using the Fisher's least significant different (LSD) test. Descriptive statistics were used to analyze demographic data and evaluate the $95 \%$ confidence intervals [14].

The alpha level for significance was set at $p<0.05$.

\section{Results}

One hundred healthy volunteers were consecutively recruited at our Research Centre. The enrolment period was from August 2018 to December 2019. Information about the characteristics of our sample (age, sex and BMI) is detailed in Table 1. 
Table 1. Information about our sample.

\begin{tabular}{cc}
\hline $\begin{array}{c}\text { Age (years) } \\
\text { mean (SD) }\end{array}$ & $29.5(12.1)$ \\
\hline $\begin{array}{c}\text { Sex } \\
\text { male/female }\end{array}$ & $41 / 59$ \\
\hline $\begin{array}{c}\text { Body mass index } \\
\text { mean (SD) }\end{array}$ & $22.0(2.4)$ \\
\hline
\end{tabular}

Abbreviations: SD, standard deviation.

Univariate ANOVA showed a significant main effect of (standing and sitting) posture on thoracic kyphosis $(p<0.001$; effect size $=0.539$; observed power $=1.000)$ and lumbar lordosis $(p<0.001$; effect size $=0.541$; observed power $=1.000$ ). Post-hoc comparisons showed a significant difference in thoracic kyphosis between conventional sitting posture vs. dynamic sitting posture $(p<0.001)$ as well as between standing posture vs. conventional sitting posture $(p<0.001)$ and standing posture vs. dynamic sitting posture $(p<0.001)$. As to the lumbar lordosis, post-hoc comparisons showed a significant difference between conventional sitting posture vs. dynamic sitting posture $(p<0.001)$ as well as between standing posture vs. conventional sitting posture $(p<0.001)$ and standing posture vs. dynamic sitting posture $(p<0.001)$. Mean data and $95 \%$ confidence intervals are reported in Table 2.

Table 2. Mean data and post-hoc comparisons.

\begin{tabular}{|c|c|c|c|c|c|c|}
\hline \multirow[t]{2}{*}{ Parameters } & \multicolumn{3}{|c|}{ Mean Data } & \multicolumn{3}{|c|}{$\begin{array}{l}\text { Post-Hoc Comparisons } \\
\text { (Fisher's LSD Test) }\end{array}$} \\
\hline & $\begin{array}{l}\text { Standing } \\
\text { posture }\end{array}$ & $\begin{array}{l}\text { Conventional } \\
\text { sitting } \\
\text { posture } \\
\end{array}$ & $\begin{array}{l}\text { Dynamic } \\
\text { sitting } \\
\text { posture } \\
\end{array}$ & $\begin{array}{c}\text { Standing vs. } \\
\text { Conventional sitting } \\
p \text { value }(95 \% \mathrm{CI})\end{array}$ & $\begin{array}{c}\text { Standing vs. } \\
\text { Dynamic sitting } \\
p \text { value }(95 \% \text { CI })\end{array}$ & $\begin{array}{l}\text { Conventional vs. } \\
\text { Dynamic sitting } \\
p \text { value }(95 \% \text { CI })\end{array}$ \\
\hline $\begin{array}{l}\text { Dorsal kyphosis }\left({ }^{\circ}\right) \\
\text { mean (SD) }\end{array}$ & $36.5(6.6)$ & $52.5(6.6)$ & $44.5(5.2)$ & $<0.001(-17.7 ;-14.2) *$ & $<0.001(-9.7 ;-6.3) *$ & $<0.001(6.2 ; 9.7)^{*}$ \\
\hline $\begin{array}{l}\text { Lumbar lordosis }\left({ }^{\circ}\right) \\
\text { mean }(\mathrm{SD})\end{array}$ & $22.0(2.4)$ & $7.0(28.2)$ & $16.6(9.2)$ & $<0.001(24.1 ; 29.8)^{*}$ & $<0.001(14.5 ; 20.2) *$ & $<0.001(-12.5 ;-6.8)$ * \\
\hline
\end{tabular}

Abbreviations: ${ }^{\circ}$, degrees; $\mathrm{SD}$, standard deviation; $\mathrm{CI}$, confidence interval. ${ }^{*}=$ statistically significant after Bonferroni correction $(p<0.016)$.

\section{Discussion}

The main aim of this study was to compare dynamic sitting vs. conventional sitting as to trunk posture adaptations on the sagittal plane (thoracic kyphosis and lumbar lordosis) in order to validate a novel (not yet on the market) dynamic stool (called "EnergyBack"). Consistent with this aim, our results evidenced on a sample of healthy people a significant difference $(p<0.001)$ between dynamic vs. conventional sitting posture as to the degrees of thoracic kyphosis and lumbar lordosis. Interestingly similar significant differences were found also between standing posture vs. dynamic sitting posture $(p<0.001)$ as well as between standing posture vs. conventional sitting posture $(p<0.001)$.

Together with the increase in hours spent in seated postures (e.g., during working or recreational activities), the incidence of musculoskeletal disorders (in particular involving the back) also appears to be rising [15]. Thus, sitting features (e.g., type of chair and its design or seat comfort) have become a main issue in the prevention of back disorders. Even if there is no consensus on "what is an optimal sitting posture", those sitting postures that match with the natural shape of the spine are deemed advantageous from a postural point of view [7-9]. To date, there is evidence about the use of chairs aimed at promoting lordotic lumbar postures, which would be associated with decreased lumbar muscle tension and improved back muscle strength [16]. The reduction in trunk muscle tension and the maintenance of "optimal" lumbar lordosis have been reported to decrease loads on the intervertebral discs [17]. Furthermore, dynamic sitting on an unstable base of support has been proposed to facilitate spinal motion during prolonged sitting in order to help prevent back muscle fatigue via alternating motor unit activation [18]. 
Spinal stability is a key factor for trunk posture [19]. It is frequently trained by using stability ball exercises, which may improve trunk endurance and contribute to postural control during prolonged sitting by training local muscles of the back (i.e., multifidus and transverse abdominis) [20]. To date, despite stability ball seating having become a trend in order to challenge trunk muscles (core activation) in the (prolonged) sitting position, the current body of evidence is not sufficient to define stability ball sitting as an effective practice to obtain a beneficial postural alignment during seated activities [17]. Furthermore (considering that stability balls are not seating devices but training ones), some safety considerations have to be carried out regarding stability ball sitting practice, which may potentially lead to falls and increase the level of seating discomfort $[17,21]$.

Core (abdominal and back) muscle activation while sitting on a dynamic chair was found comparable to that on a stability ball [22]. On this basis, and taking into account the number of positive issues about dynamic sitting mentioned above, some tools have been proposed to promote trunk posture, movement and exercise during prolonged sitting [5,15,23,24].

From our point of view, thinking about a novel seating device to be conceived in line with the dynamic and "stability ball" sitting approaches but able to overcome (almost in part) their limits (such as safety and comfort), we developed the "EnergyBack", which is a novel dynamic stool with an unstable base of support given by a ball positioned between the seat and the stool base (see Figure 1). The moving seat is fixed to the stool base by means of four elastic ropes, which enable two-dimensional swinging of the seating area and allow the dynamic stool components (seat, ball and base) to be centered on the same main vertical axis. The dynamic stool base has an adjustable height. The "EnergyBack" was built mainly with the aim to promote the preservation of physiological sagittal spinal curvature (thoracic kyphosis and lumbar lordosis) during sitting posture. The current findings validate the first aim of this device. Indeed, even if none of the sitting conditions (dynamic and conventional) was able to match completely with the "ideal" spinal posture (natural spinal curves on the sagittal plane evaluated in standing), considering their mean values (see Table 2), we argue that thoracic kyphosis and lumbar lordosis measured in the dynamic sitting condition ("EnergyBack" device) get significantly closer to the sagittal curvatures of the spine evaluated in standing posture than those assessed in the conventional sitting condition (standard stool). Thus, we claim for a better trunk posture alignment during sitting given by the dynamic stool than the standard one in our healthy volunteers.

This validation study has some limitations. First of all, the design was not prospective and considered only the "short term" adaptations of trunk posture induced by the "EnergyBack" dynamic stool. So, we cannot infer its effects on trunk posture in terms of prolonged sitting and routine use (e.g., back pain prevention). Furthermore, we included only healthy people, so we cannot draw any conclusion about the effects of our dynamic stool on patients with back pain. Third, we did not test sitting posture during some daily common tasks such as reading, writing by hand, calling or typing on the keyboard. Fourth, no instrumental kinematic (e.g., motion analysis) and neurophysiological (e.g., surface electromyography) evaluation was carried out. Fifth, we did not include any evaluation of compliance with the novel dynamic stool tested in this study.

\section{Conclusions}

Sitting on the novel dynamic stool tested in this study was shown to provide a greater match of thoracic kyphosis and lumbar lordosis with the physiological spinal curvature on sagittal plane during standing than conventional sitting. Future studies would consider the limitation mentioned above in order to overcome them and further validate the effects of this novel dynamic stool. In our opinion, it would be interesting to test the effects of "EnergyBack" on patients with back pain or poor posture. On this line, "EnergyBack" might be tested (and hopefully used in the case of positive evidence) as a tool for postural rehabilitation. 


\section{Patents}

The device validated by this study was recently patented (Italian Registry no. 102016000118233) but not yet commercialized.

Author Contributions: Conceptualization, A.P., G.M. and N.S.; methodology, A.P. and N.S.; formal analysis, A.P.; investigation, A.P.; data curation, A.P.; writing-original draft preparation, A.P.; writing-review and editing, G.M. and N.S.; supervision, N.S. All authors have read and agreed to the published version of the manuscript.

Funding: This research received no external funding.

Conflicts of Interest: The authors are patent holders of this device. The authors declare no conflict of interest.

\section{References}

1. Maher, C.; Underwood, M.; Buchbinder, R. Non-specific low back pain. Lancet 2017, 389, 736-747. [CrossRef]

2. O'Keeffe, M. Non-pharmacological treatment of low back pain in primary care. Drug Ther. Bull. 2019, 57, 104-108. [CrossRef] [PubMed]

3. Oliveira, C.B.; Maher, C.G.; Pinto, R.Z.; Traeger, A.C.; Lin, C.C.; van Tulder, M.; Koes, B.W. Clinical practice guidelines for the management of non-specific low back pain in primary care: An updated overview. Eur. Spine J. 2018, 27, 2791-2803. [CrossRef] [PubMed]

4. Vlaeyen, J.W.S.; Maher, C.G.; Wiech, K.; Van Zundert, J.; Meloto, C.B.; Diatchenko, L.; Battié, M.C.; Goossens, M.; Koes, B.; Linton, S.J. Low back pain. Nat. Rev. Dis. Primers 2018, 4, 52. [CrossRef]

5. O'Sullivan, K.; McCarthy, R.; White, A.; O'Sullivan, L.; Dankaerts, W. Lumbar posture and trunk muscle activation during a typing task when sitting on a novel dynamic ergonomic chair. Ergonomics 2012, 55, 1586-1595. [CrossRef] [PubMed]

6. Czaprowski, D.; Stoliński, L.; Tyrakowski, M.; Kozinoga, M.; Kotwicki, T. Non-structural misalignments of body posture in the sagittal plane. Scoliosis Spinal. Disord. 2018, 13, 6. [CrossRef]

7. Claus, A.P.; Hides, J.A.; Moseley, G.L.; Hodges, P.W. Is 'ideal' sitting posture real? Measurement of spinal curves in four sitting postures. Man. Ther. 2009, 14, 404-408. [CrossRef]

8. O'Sullivan, K.; O'Sullivan, P.; O'Sullivan, L.; Dankaerts, W. What do physiotherapists consider to be the best sitting spinal posture? Man. Ther. 2012, 17, 432-437. [CrossRef]

9. Korakakis, V.; O'Sullivan, K.; O'Sullivan, P.B.; Evagelinou, V.; Sotiralis, Y.; Sideris, A.; Sakellariou, K.; Karanasios, S.; Giakas, G. Physiotherapist perceptions of optimal sitting and standing posture. Musculoskelet. Sci. Pract. 2019, 39, 24-31. [CrossRef]

10. Synnott, A.; Dankaerts, W.; Seghers, J.; Purtill, H.; O'Sullivan, K. The effect of a dynamic chair on seated energy expenditure. Ergonomics 2017, 60, 1384-1392. [CrossRef]

11. Alderighi, M.; Ferrari, R.; Maghini, I.; Del Felice, A.; Masiero, S. Intra and interrater reliability of spinal sagittal curves and mobility using pocket goniometer IncliMed ${ }^{\circledR}$ in healthy subjects. J. Back Musculoskelet. Rehabil. 2016, 29, 873-880. [CrossRef] [PubMed]

12. Gravina, A.; Ferraro, C.; Poli, P.; Barazzuol, M.; Del Felice, A.; Masiero, S. Goniometric evaluation of the spinal sagittal curves in children and adolescents: A reliability study. J. Back Musculoskelet. Rehabil. 2017, 30, 325-331. [CrossRef] [PubMed]

13. Picelli, A.; Negrini, S.; Zenorini, A.; Iosa, M.; Paolucci, S.; Smania, N. Do adolescents with idiopathic scoliosis have body schema disorders? A cross-sectional study. J. Back Musculoskelet. Rehabil. 2016, 29, 89-96. [CrossRef] [PubMed]

14. Cohen, J. Statistical Power Analysis for the Behavioral Sciences, 2nd ed.; Lawrence Erlbaum: Hillsdale, NJ, USA, 1988.

15. Ellegast, R.P.; Kraft, K.; Groenesteijn, L.; Krause, F.; Berger, H.; Vink, P. Comparison of four specific dynamic office chairs with a conventional office chair: Impact upon muscle activation, physical activity and posture. Appl. Ergon. 2012, 43, 296-307. [CrossRef]

16. Koskelo, R.; Vuorikari, K.; Hänninen, O. Sitting and standing postures are corrected by adjustable furniture with lowered muscle tension in high-school students. Ergonomics 2007, 50, 1643-1656. [CrossRef] [PubMed]

17. Lowe, B.D.; Swanson, N.G.; Hudock, S.D.; Lotz, W.G. Unstable sitting in the workplace are there physical activity benefits? Am. J. Health Promot. 2015, 29, 207-209. [CrossRef]

18. van Dieën, J.H.; de Looze, M.P.; Hermans, V. Effects of dynamic office chairs on trunk kinematics, trunk extensor EMG and spinal shrinkage. Ergonomics 2001, 44, 739-750. [CrossRef] [PubMed] 
19. Granata, K.P.; Wilson, S.E. Trunk posture and spinal stability. Clin. Biomech. (Bristol. Avon.) 2001, 16, 650-659. [CrossRef]

20. Carter, J.M.; Beam, W.C.; McMahan, S.G.; Barr, M.L.; Brown, L.E. The effects of stability ball training on spinal stability in sedentary individuals. J. Strength Cond. Res. 2006, 20, 429-435. [PubMed]

21. Gregory, D.E.; Dunk, N.M.; Callaghan, J.P. Stability ball versus office chair: Comparison of muscle activation and lumbar spine posture during prolonged sitting. Hum. Factors 2006, 48, 142-153. [CrossRef]

22. Holmes, M.W.; De Carvalho, D.E.; Karakolis, T.; Callaghan, J.P. Evaluating abdominal and lower-back muscle activity while performing core exercises on a stability ball and a dynamic office chair. Hum. Factors 2015, 57, 1149-1161. [CrossRef]

23. Doroff, C.E.; Langford, E.L.; Ryan, G.A.; Snarr, R.L. Effects of active sitting on reading and typing task productivity. Int. J. Exerc. Sci. 2019, 12, 1216-1224.

24. Nüesch, C.; Kreppke, J.N.; Mündermann, A.; Donath, L. Effects of a dynamic chair on chair seat motion and trunk muscle activity during office tasks and task transitions. Int. J. Environ. Res. Public Health 2018, 15, 2723. [CrossRef] [PubMed]

Publisher's Note: MDPI stays neutral with regard to jurisdictional claims in published maps and institutional affiliations.

(C) 2020 by the authors. Licensee MDPI, Basel, Switzerland. This article is an open access article distributed under the terms and conditions of the Creative Commons Attribution (CC BY) license (http://creativecommons.org/licenses/by/4.0/). 